\title{
Prevalence of Cysticercus bovis in slaughtered cattle determined by traditional meat inspection in Croatian abattoir from 2005 to 2010
}

\author{
N. ZDOLEC ${ }^{1}$, I. VUJEVIĆ ${ }^{2}$, V. DOBRANIĆ ${ }^{1}$, M. JURAS ${ }^{2}$, N. GRGUREVIĆ ${ }^{3}$, D. ARDALIĆ ${ }^{4}$, B. NJARI ${ }^{1}$
}

\author{
${ }^{1}$ University of Zagreb, Faculty of Veterinary Medicine, Department of Food Hygiene, Technology and Safety, 10000 \\ Zagreb, Heinzelova 55, Croatia, E-mail: nzdolec@vef.hr; ${ }^{2}$ Veterinary Station Vrbovec, 10340 Vrbovec, \\ Kolodvorska 68, Croatia, E-mail: vet.insp@pik-vrbovec.hr; ${ }^{3}$ Konmarklab d.o.o., Medvedgradska 49, 10000 Zagreb, \\ Croatia, E-mail:vragovic@ckh.hr; ${ }^{4}$ Meat industry PIK, 10340 Vrbovec, Zagrebačka 148, Croatia, \\ E-mail:vet.insp@pik-vrbovec.hr
}

\begin{abstract}
Summary
The aim of this work was to evaluate the presence of Cysticercus bovis of slaughtered cattle in a Croatian slaughterhouse between 2005 and 2010. In total, 203166 carcasses and organs were examined, of which in $228 \mathrm{C}$. bovis was found $(0.11 \%)$. The highest number of cysticercosis was found in cows $(0.69 \%, \mathrm{n}=13605)$, then in steers $(0.093 \%$; $\mathrm{n}=134212)$, and the lowest in calves $(0.014 \%$; $=55349)$. Among the 228 positive specimens, $129(56.57 \%)$ came from rural estates and $99(43.43 \%)$ from farms. The ratio of invaded steers from rural estates $(\mathrm{n}=2790)$ and from farm breed $(\mathrm{n}=131422)$ was $1.075 \%: 0.064 \%$, calves $(\mathrm{n}=$ 316 and $\mathrm{n}=55033) 0.316 \%: 0.012 \%$, and cows $(\mathrm{n}=8985$ and $n=4620) 097 \%: 0.15 \%$. The number of cysticercosis invaded cattle decreased from the initial $0.37 \%$ to $0.07 \%$. Despite low prevalence, we consider that each positive result requires an individual epidemiologic study in order to decrease the risk even more.
\end{abstract}

Keywords: cysticercosis; cattle; meat inspection

\section{Introduction}

Statistical data on the presence of cattle cysticercosis in certain countries or regions are not complete or reliable, given that there is no legal obligation of denouncing this zoonosis. It is also important to mention that the estimation of the presence of this cattle disease largely depends on the detection methodology employed (Edwards et al., 1997). In European countries, the presence of cysticercosis in cattle range from $0.007 \%$ to $6.8 \%$ (Cabaret et al., 2002; Boone et al., 2007; Allepuz et al., 2009). However, it is important to mention that only a few EU countries submit reports to the World Animal Health Organisation, thus the statistical data are not representative enough to draw any kind of conclusions about the distribution of this disease in Europe. It is well known that teniasis and cysticercosis are the most important problem of the public health in African and Asian countries (Kebede, 2008; Qadeer, 2008; Kebede et al., 2009; Rabi'u \& Jegede, 2010; Khaniki et al., 2010), but the risk could be present elsewhere (Rudohradská et al., 2012).

The available data on the presence of $C$. bovis in cattle determined by traditional meat inspection in our region (Western Balkans) indicate a diversity in prevalence (from $0.43 \%$ to $22.4 \%$ ), which largely depends on the number of examined animals, their age, origin, the breeding manner, etc. (Francetić, 1958; Burić, 1975; Velimirović, 1992; Živković et al., 1996; Zdolec et al., 2012). During the last two decades there were no reports on bovine cysticercosis prevalence in Croatia. Having in mind the future modernisation of meat inspection and the need for harmonized monitoring and reporting scheme of cysticercosis (Dorny et al., 2010), the aim of this work was to present the prevalence of C. bovis in cattle slaughtered between 2005 and 2010 in Croatian export abattoir. The presence of the cysticercosis in relation with the origin and the age of slaughtered cattle during the observed period will be analyzed.

\section{Materials and methods}

\section{Cattle carcasses and organs}

The research will analyze the results of post mortem inspection of cattle slaughtered in a local slaughterhouse from 2005 to 2010. There were 55349 calves, 134212 steers and 13605 cows slaughtered. Among them, 316 calves, 2790 steers and 8985 cows came from Croatian rural estates, while the rest were bred on farms (Tables 1,2).

\section{Meat and organs' testing on C. bovis}

The post mortem inspection was done in accordance to the regulation in force in the year of research. Until 2007, the Regulation on the Methods of Conducting a VeterinarySanitary Inspection and on the Control of Animals before Slaughtering and of Animal Origin Products (Anon, 1991) 
Table 1. The number of slaughtered cattle from 2005 to 2010

\begin{tabular}{lcccccc}
\hline & \multicolumn{7}{c}{ Years } \\
& $\mathbf{2 0 0 5}$ & $\mathbf{2 0 0 6}$ & $\mathbf{2 0 0 7}$ & $\mathbf{2 0 0 8}$ & $\mathbf{2 0 0 9}$ & $\mathbf{2 0 1 0}$ \\
\hline Calves & 5869 & 11012 & 12851 & 12292 & 5428 & 7897 \\
Steers & 12034 & 19901 & 26302 & 26064 & 24171 & 25740 \\
Cows & 2153 & 3754 & 2776 & 1756 & 1421 & 1745 \\
Total & 20056 & 34667 & 42929 & 40112 & 31020 & 35382
\end{tabular}

was in force. Since 2007, the revisions are done in accordance with the Regulation on the Hygiene of Food of Animal origin (Anon, 2007), which is Croatian version of EC Regulation No 854/2004. During the post mortem cattle meat and organs' testing on $C$. bovis, skeletal and heart muscles are examined by cutting $m$. masseter, $m$. pterygoideus and septum cordis, and by tongue and oesophagus palpation, as well as by inspecting of other visible muscles (diaphragm, etc.) or, if necessary, cutting into them.

\section{Statistic processing}

The research results were processed by Microsoft Office Excel 2007 and Statistic 9 (StatSoft, Tulsa, USA). results indicates a correlation between the age of animals and the larva presence. It is evident that the lowest percentage of invaded animals was found among calves, then steers, and the highest among cows.

\section{Discussion}

Our results demonstrate low prevalence of $C$. bovis given the high number of the examined carcasses and organs, and, as compared to the previous researches in our region (Francetić, 1958; Burić, 1975; Stamenković, 1992; Živković et al., 1996), the percentage of invaded cattle was considerably lower. Our result of $0.11 \%$ of invaded cattle is within the European average according to Cabaret et al. (2002). Boone et al. (2007) recorded a $2-4$ times higher percentage of invaded cattle in Belgium, while Spanish authors (Allepuz et al., 2009) reported a ten times lower prevalence of cysticercosis than shown by our research. Allepuz et al. (2009) registered a slight increase (2005 2007), but they attribute it to the more thorough veterinarian revision, not to higher prevalence of disease. Our research did not detect this kind of regularities as regarding the increase/decrease of the number of invaded cattle during the

Table 2. The number of slaughtered calves, steers and cows form 2005 to 2010 according to the breeding manner (rural estate or farm)

\begin{tabular}{llllllll}
\hline & & \multicolumn{7}{c}{ Years } \\
& Breeding & $\mathbf{2 0 0 5}$ & $\mathbf{2 0 0 6}$ & $\mathbf{2 0 0 7}$ & $\mathbf{2 0 0 8}$ & $\mathbf{2 0 0 9}$ & $\mathbf{2 0 1 0}$ \\
\hline \multirow{2}{*}{ Calves } & Rural estate & 17 & 41 & 23 & 15 & 19 & 201 \\
& Farm & 5852 & 10971 & 12828 & 12277 & 5409 & 7696 \\
& Rural estate & 234 & 95 & 204 & 1074 & 114 & 1249 \\
\multirow{2}{*}{ Cows } & Farm & 11800 & 19806 & 26098 & 24990 & 24057 & 24491 \\
& Rural estate & 1245 & 2747 & 1758 & 1501 & 976 & 758 \\
& Farm & 908 & 1007 & 1018 & 255 & 445 & 987
\end{tabular}

\section{Results}

The aim of this work was to represent the results of post mortem cattle inspection (calves, steers and cows) done in the export abattoir from 2005 to 2010 , as related to the presence of $C$. bovis. During the observed period, 203166 animals were slaughtered in this object, which is averagely 33861 a year. According to the data provided by the Croatian Bureau of Statistics, during the same period, 1212124 animals were slaughtered in whole country, which means $16.7 \%$ of the total number were slaughtered in our abattoir.

The results of $C$. bovis determination are presented in the Tables 3 and 4. Traditional post mortem inspection detected 228 positive cattle to $C$. bovis, which, given the total number of slaughtered cattle $(n=203166)$, makes $0.11 \%$ (Table 4 ). According to the individual categories of cattle, the percentage of $C$. bovis positive was $0.014 \%$ in calves $(\mathrm{n}=55349), 0.093 \%$ in steers $(\mathrm{n}=134212)$ and $0.69 \%$ in cows $(n=13605)$. If we exclude the specimen size from the analysis of cysticercosis' frequency, these 230 observed period of six years. The correlation between the $C$. bovis frequency and the cattle age that we found is expected, because older animals are exposed to risk for a longer period of time, as well as to a greater possibility of re-invasion. The results of Allepuz et al. (2009), which report a higher frequency of $C$. bovis on dairy cows' farms as compared to the farms of beef steers, go in this direction, too.

Table 3. The number of Cysticercus bovis positive results in slaughtered calves, steers and cows from 2005 to 2010

\begin{tabular}{lcccccc}
\hline & $\mathbf{2 0 0 5}$ & $\mathbf{2 0 0 6}$ & $\mathbf{2 0 0 7}$ & $\mathbf{2 0 0 8}$ & $\mathbf{2 0 0 9}$ & $\mathbf{2 0 1 0}$ \\
\hline Calves & 3 & 0 & 0 & 1 & 3 & 1 \\
Steers & 32 & 12 & 26 & 25 & 10 & 20 \\
Cows & 40 & 5 & 21 & 16 & 10 & 3 \\
Total & 75 & 17 & 47 & 42 & 23 & 24 \\
\%* & 0.37 & 0.049 & 0.1 & 0.1 & 0.07 & 0.067 \\
\hline
\end{tabular}

$* \overline{\text { percentage of positives in total number of slaughter cattle in each year }}$ 
Table 4. Distribution of invaded calves, steers and cows slaughtered from 2005 to 2010 according to the breeding manner (rural estate or farm)

\begin{tabular}{llcccccc}
\hline & & \multicolumn{7}{c}{ Years } \\
& Breeding manner & $\mathbf{2 0 0 5}$ & $\mathbf{2 0 0 6}$ & $\mathbf{2 0 0 7}$ & $\mathbf{2 0 0 8}$ & $\mathbf{2 0 0 9}$ & $\mathbf{2 0 1 0}$ \\
\hline \multirow{2}{*}{ Calves } & Rural estate & 1 & 0 & 0 & 0 & 0 & 0 \\
& Farm & 2 & 0 & 0 & 1 & 3 & 1 \\
\multirow{3}{*}{ Steers } & Rural estate & 5 & 5 & 8 & 12 & 4 & 6 \\
& Farm & 27 & 7 & 18 & 13 & 6 & 14 \\
\multirow{2}{*}{ Cows } & Rural estate & 38 & 5 & 21 & 13 & 9 & 2 \\
& Farm & 2 & 0 & 0 & 3 & 1 & 1 \\
\hline
\end{tabular}

According to the data from the Table 4, it is evident that, among the total number of invaded cattle $(\mathrm{n}=228)$, higher number come from rural estates $(n=129,56.57 \%)$ than from farms $(\mathrm{n}=99,43.43 \%)$. Observed individually, that is, according to the categories of slaughtered cattle, the situation is different, so that a higher number of invaded calves and steers were farm bred. Thus, the ratio of invaded calves was $7: 1$ on the farm calves side ( 7 invaded), and an importantly higher number of invaded steers came from farms $(n=85)$ than from rural estates $(n=30)$. Hence, among the total number of invaded steers during the observed period $(\mathrm{n}=125), 68 \%$ came from farms, and $32 \%$ from rural estates. However, these comparisons are only partly relevant, since the number of slaughtered steers coming from farms was several times higher $(n=131422)$ than the number of those coming from rural estates $(\mathrm{n}=$ 2790 ). Furthermore, if we reduce the number of positive results to the observed specimen, the percentage of invaded calves on farms is $0.064 \%(\mathrm{n}=131422)$, and that on rural estates is $1.075 \%(n=2790)$. The invasion in calves, which appears to be more frequent on farms, can be analyzed in a similar way. The number of slaughtered calves from farms was 55 033, and from rural estates only 316 . In analogy with the previous example, the ratio of invaded calves from farms and those from rural estates would be 0 . $012 \%: 0.316 \%$. Therefore, we can conclude that the frequency of invasion in calves and steers slaughtered in monitored abattoir from 2005 to 2010 was higher in animals coming from rural estates than in those coming from farms. As it is shown in the Table 4, the number of invaded cows from rural estates was significantly higher $(n=88)$ than that from farms $(n=7)$. The percentage of invaded cows from rural estates and farms in the total number of slaughtered cows $(n=13605)$ during the observed period was $0.64 \%$ and $0.05 \%$, respectively. Observing the number of invaded cows in relation to the group they belong to (rural estates: $n=8985$, farms $n=4620$ ), a greater frequency of invaded cows coming from rural estates is again evident $(0.97 \%: 0.15 \%)$. The results of other researches also demonstrated a higher frequency of $C$. bovis in cattle coming from extensive breeding (Burić, 1975; Dorny et al., 2002).

Observing the results according to the year in which the research was conducted, it is evident that the number of invaded cattle decreased from the initial $0.37 \%$ (in 2005) to only $0.07 \%$ (in 2010 ), which could be the result of the influence of several factors - the number of inspected cattle, their origin, the real decrease of cysticercosis prevalence and the procedure of post mortem inspection. When comparing the initial prevalence $(0.37 \%)$ to the following years of research, it is important to note that in 2005, $1.5-$ 2 times less cattle was slaughtered. The decrease of prevalence is also evident when observing individual categories of cattle: in steers from $0.26 \%$ (in 2005) to $0.07 \%$ (in 2010), and in cows from the high $1.85 \%$ (in 2005) to $0.17 \%$ (in 2010). The sudden decrease of invaded cows in 2006, as compared to 2005 (tenfold) is especially noticeable, while the percentage of invaded animals increased again 5 - 7 times from 2007 to 2009 . However, in the end of the observed period (in 2010), the percentage of invaded cows was almost at the 2006 level $(0.17 \%)$.

Finally, we can conclude that the presence of $C$. bovis in cattle slaughtered in monitored Croatian abattoir is rare $(0.11 \%)$, but, nonetheless, we consider that each positive result requires an individual epidemiologic study of the corresponding estate or farm, in order to decrease the risk even more. In this sense, the veterinary inspection service plays an important role, but it is necessary to relate it better to all the corresponding veterinary organizations and authorities, so that its positive findings on the slaughter line would be followed by adequate measures in primary production on the estate/farm in question. Furthermore, we consider it reasonable to prescribe the obligation of additional sampling and analysis (serology, etc), at the level of estate/farm or slaughterhouse, for each estate/farm from which invaded cattle comes repeatedly. From the epidemiological point of view, it is also important to conduct confirmation tests that is to confirm/reject each positive finding on the slaughter line by pathohistological, immunochemical or molecular tests. This way, after a certain period of time, we could draw conclusions about the real epidemiological situation of cattle cysticercosis in Croatia and about the reliability of certain methods of monitoring of this disease.

\section{References}

Allepuz, A., Napp, S., Picado, A., Alba, A., Panades, J., DomingO, M., CASAL, J. (2009): Descriptive and spatial epidemiology of bovine cysticercosis in North-Eastern 
Spain (Catalonia). Vet. Parasitol., 159(1): 43 - 48. DOI: 10.1016/j.vetpar.2008.09.027

ANONYMOUS (1991): Regulation on the methods of conducting a veterinary-sanitary inspection and on the control of animals before slaughtering and of animal origin products. Official Gazette 68/1989; 53/1991.

ANONYMOUS (2007): Regulation on the hygiene of food of animal origin. Official Gazette 99/2007.

Boone, I., Thys, E., Marcotty, T., De Borchgrave, J., DuCHEYne, E., DoRnY, P. (2007): Distribution and risk factors of bovine cysticercosis in Belgian dairy and mixed herds. Prev. Vet. Med., 82(1 - 2): 1 - 11. DOI: 10.1016/ j.prevetmed.2007.05.002

BURIĆ, M. (1975): Contribution of knowledge of occurrence of bovine cysticercosis in MIM abattoir in relation to animal origin and meat inspection. Master thesis, Serbia, Zemun: Faculty of Agriculture Zemun.

Cabaret, J., Geerts, S., Madeline, M., Ballandonne, C., BARBIER, D. (2002): The use of urban sludge on pastures: the cysticercosis threat. Vet. Res., 33(5): 575 - 597. DOI: $10.1051 /$ vetres:2002040

Dorny, P., Phiri, I., Gabriel, S., Speybroeck, N., VERCRUYSSE, J. (2002): A sero-epidemiological study of bovine cysticercosis in Zambia. Vet. Parasitol., 104(3): 211 - 215. DOI: 10.1016/S0304-4017(01)00634-3

DORnY, P., PRAET, N. (2007): Taenia saginata in Europe. Vet. Parasitol., 149(1-2): 22 - 24. DOI: $10.1016 /$ j.vet par.2007.07.004

Dorny, P., Vallée, I., Alban, L., Boes, J., Boireau, P., Boué, F., Claes, M., CoOK, A. J. C., Enemark, H., Van Der Giessen, J., Hunt, K. R., Howell, M., KirJuŠina, M., NÖCKLER, K., PozIO, E., Rossi, P., SNOW, L., TAYlOR, M. A., Theodoropoulos, G., Vieira-Pinto, M. M., ZIMMER, I. A. (2010): Development of harmonised schemes for the monitoring and reporting of Cysticercus in animals and foodstuffs in the European Union. Scientific report submitted to EFSA. Retrieved April 7, 2012 from http://www.efsa.europa.eu/en/supporting/doc/34e.pdf.
Edwards, D. S., Johnston, A. M., Mead, G. C. (1997): Meat inspection:an overview of present practices and future trends. Vet. J., 154(2): 135 - 147. DOI: 10.1016/S1090-0233(97)80051-2

KEBEDE, N. (2008): Cysticercosis of slaughtered cattle in northwestern Ethiopia. Res. Vet. Sci. 85(3): 522 - 526. DOI: 10.1016/j.rvsc.2008.01.009

Kebede, N., Tilahun, G., Hailu, A. (2009): Current status of bovine cysticercosis of slaughtered cattle in Addis Ababa Abattoir, Ethiopia. Trop. Anim. Health Prod., 41(3): 291 - 294. DOI: 10.1007/s11250-008-9188-4

Khaniki, G. H. J. R., Raei, M., Kia, E. B., Motevalli, H. A., SElseleh, M. (2010): Prevalence of bovine cysticercosis in slaughtered cattle in Iran. Trop. Anim. Health Prod., 42(2): 141 - 143. DOI: $10.1007 / \mathrm{s} 11250-009-9399-3$

RABI'U, B. M., JEGEDE, O. C. (2010): Incidence of bovine cysticercosis in Kano State, Northwestern, Nigeria. BAJOPAS, 3(1): 100 - 103

RudohradsKá, P., HalánOVÁ, H., Ravaszová, P., GoldovÁ, M., VAlENČÁKOVÁ, A., HALÁN, M., PAPAJOVÁ, I., Pohorencová, A., VAlKo, J., ČISlÁKOVÁ, L., Juriš, P. (2012): Prevalence of intestinal parasites in children from minority group with low hygienic standards in Slovakia. Helminthologia, 49(2): 63 - 66. DOI: 10.2478/s11687012-0013-2

QADEER, M. A. (2008): Prevalence of bovine cysticercosis in Jos abattoir, Nigeria. Anim. Res. Int., 5(1): 777 - 779

VELIMIROVIĆ, D. (1992): Signifficante of Cysticercus bovis s. inermis in assessment of hygienic correctnes of cattle meat. Master thesis. Zagreb, Croatia: Faculty of Veterinary Medicine, University of Zagreb.

Zdolec, N., VujeVić, I., Dobranić, V., ŽUŽUl, D., VuKŠić, F., PeraK, Z., VALUŠEK, A., NJARI, B. (2012): Significance of bovine cysticercosis in veterinary public health. Veter. stan., 43(4): $319-325$

ŽIvković, J., Velimirović, D., DŽAJA, P., Grabarević, Ž. (1996): Prevalence of Cysticercus bovis s inermis measles with particular reference to histopathological changes in meat. Arch. Lebensmittelhyg., 47(3): 66-68 